\title{
Clinical and laboratory variables associated with quality of life in Brazilian haemodialysis patients: a single-centre study
}

\author{
Paulo Roberto Santos ${ }^{1}$, Lígia Regina Franco Sansigolo Kerr².
}

Background: Amongst chronic diseases, end-stage renal disease (ESRD) deserves special attention in the context of health-related quality of life (HRQOL). ESRD affects quality of life more intensely than heart failure, diabetes, chronic lung disease, arthritis and cancer. In addition, patients who perceive low HRQOL withdraw from dialysis treatment more commonly. Aim: To identify clinical and laboratory variables associated with health-related quality of life (HRQOL) in hemodialysis (HD) patients. Patients and methods: We included 174 chronic HD patients from a single unit aged 18 years and older who never received a kidney allograft and survived the first three months of treatment. We used the Khan index to assess comorbidity and the Medical Outcomes Study 36-Item Short Form Health Survey Questionnaire (SF-36) to measure HRQOL Results: Amongst the eight domains of HRQOL, physical role had the lowest score (35.0 \pm 43.0$)$ and social function the highest (64.3 \pm 27.7$)$. In the multivariate analysis, age was associated with seven of eight domains, excepting bodily pain. Albumin was associated with five of eight domains. Time on dialysis, hemoglobin and calcium-phosphorus product were associated with physical function, bodily pain and vitality, respectively. Conclusions: Age and albumin were the main variables associated with quality life, and the calcium-phosphorus product was associated with a strategic domain: vitality. Attention to albumin and ageing effects, control of the calcium-phosphorus product and improvement of physical conditioning are necessary to achieve better HRQOL (Rev Méd Chile 2008; 136: 1264-71).

(Key words: Calcium-phosphorus; Hemodiafiltration; Quality of life; Serum albumin)

\section{Variables clínicas y de laboratorio asociadas a la calidad de vida de pacientes brasileños en hemodiálisis. Estudio de un centro}

Antecedentes: La enfermedad renal terminal afecta la calidad de vida relacionada a salud más que la insuficiencia cardíaca, la diabetes, enfermedad pulmonar crónica y cáncer. Los pacientes que tienen una baja calidad de vida, se retiran de los tratamientos dialíticos con más frecuencia. Objetivo: Identificar variables clínicas y de laboratorio asociadas a la calidad de vida relacionada a salud, en pacientes en hemodiálisis crónica. Pacientes y método: Se estudiaron 174 pacientes en hemodiálisis crónica, mayores de 18 años y que nunca hubieran recibido un trasplante renal. Se utilizó el índice de Khan para evaluar comorbilidades y el cuestionario SF-36 (36-Item Short Form Health Survey Questionnaire) para evaluar calidad de vida relacionada a salud. Resultados: De los ocho dominios que comprende el cuestionario, el rol físico obtuvo el puntaje más bajo (35.0 \pm 43.0 ) y la función social, el más alto (64.3×27.7). En el análisis multivariado, la edad estaba asociada con siete de los ocho dominios, exceptuando dolor corporal. La albúmina estaba asociada con cinco de los ocho dominios. El tiempo en diálisis, la hemoglobina y el producto calcio-fósforo se asociaron con función física, dolor corporal y vitalidad, respectivamente. Conclusiones: La edad y albúmina fueron las variables más asociadas a calidad de vida. El producto calcio-fósforo se asoció a vitalidad, un dominio estratégico. Para mejorar la calidad de vida, se debe prestar atención a la albúmina y los efectos del envejecimiento, se debe controlar el producto calcio-fósforo y mejorar la condición física.

Recibido el 3 de marzo, 2008. Aceptado el 21 de junio, 2008.

Disclosures: The authors declare that there is no conflict of interest regarding this original article, and they did not receive any financial support for this work.

${ }^{1}$ Postgraduate Program in Medical Sciences, Federal University of Ceará, Fortaleza, Ceará, Brazil. 2Department of Community Health, School of Medicine, Federal University of Ceará, Fortaleza, Ceará, Brazil. 
$\mathrm{T}$ raditionally, clinical variables are used in medical practice to tailor interventions and determine prognosis concerning organ dysfunction and death. In chronic disease states, another outcome must be put in perspective, since medical technology can postpone death and minimize some organic complications, but throughout the lifetime the morbid condition affects many dimensions of patients' daily activities. In fact, quality of life is perceived by patients as being an important outcome in the scenario of chronic diseases.

Health-related (HRQOL) is associated with the various aspects of life that are affected by a person's health status ${ }^{1}$. During the 1990s there was a large increase in medical research about HRQOL' ${ }^{2}$. Nowadays HRQOL, along with efficacy and security, is a primary outcome in many clinical trials. There are some well-validated instruments to measure HRQOL in patients as well as the general population. However, the high cost involved in validating such instruments inhibits creation of new instruments. SF-36 is being widely used in medical research and to measure population life quality parameters in many countries.

Amongst chronic diseases, end-stage renal disease (ESRD) deserves special attention in the context of HRQOL ESRD affects quality of life more intensely than heart failure, diabetes, chronic lung disease, arthritis and cancer ${ }^{3}$. In addition, patients who perceive low HRQOL withdraw from dialysis treatment more frequently ${ }^{4}$. Perhaps no other marker can indicate this risk. Indeed, withdrawal is responsible for one-fourth of deaths in haemodialysis (HD) patients 5 . Unfortunately, kidney transplants, which offer the best life quality, are not accessible to many patients because of the worldwide shortage of organs ${ }^{6,7}$. Hence, reliable associations of objective variables, such as from clinical or laboratory studies, are useful for health professionals involved in caring for HD patients.

Due to the multifactorial profile of HRQOL, it is not surprising that researchers find a multiplicity of associations, especially in multicentric studies with large samples ${ }^{8}$. Since 2004 we have been focusing on HRQOL regarding a small sample from a single renal unit, the only one in the northern region of Ceará state in northeast Brazil. The clinical characteristics of this sample, however, are similar to those in other underdeveloped areas: young patients with low-comorbidity. There is a great deal of research from developing countries about HRQOL in older, high-comorbidity and diabetic patients, but ESRD can affect patients of any age. Nephrologists all over the world, particularly in South America, care for poor patients with clinical characteristics of our sample and need more data about them. Thus, we aimed to identify what clinical and laboratory variables are independently associated with HRQOL in HD patients at a single dialysis unit in northeast Brazil.

\section{PATIENTS AND METHODS}

Sample. The study was performed at the Dialysis Unit of Santa Casa Hospital, in Sobral, Ceará, Brazil. From March 2004 to March 2006, we included consecutive ESRD patients older than 18 years of age undergoing haemodialysis for at least three months, who had not received transplants. Amongst 139 patients on HD in March 2004, 108 were included. The reasons for leaving the others out were: 16 with less than three months on haemodialysis, 4 had previously received transplants, 7 patients refused and 4 were under 18 years of age. Until the end of the study in March 2006, a further 56 patients were included. During the study period, the only reason for exclusion was the death of 29 patients before three months on haemodialysis. Thus, there were 164 participants in the study. All patients were submitted to conventional HD (three times a week) with polysulfone dialysers (maximum number of reuse $=12$ ). The study protocol and informed consent were approved by the ethics committee of the Federal University of Ceará.

Measurement of quality of life. We used the validated Brazilian version of the Medical Outcomes Study 36-Item Short Form Health Survey Questionnaire (SF-36) to measure the HRQOL level $^{9}$. This is a well-validated 36-item questionnaire covering issues relating to physical, psychological and social functioning that generates scores from 0 (worst) to 100 (best) concerning 8 domains: physical function (PF), role-physical (RP), bodily pain (BP), general health (GH), vitality (VT), social function (SF), role-emotional (RE) and mental health (MH). PF scores patients' 
performance related to daily activities, RP regards the impact of physical health on life, BP evaluates pain level and its impact on normal daily activities, GH evaluates subjective perception about present and future health status and resistance to illness, VT scores patients' feelings about their energy, vitality and moments of fatigue, SF scores the impact of health on routine social activities, $\mathrm{RE}$ measures the influences of emotional status on daily activities, and $\mathrm{MH}$ scores humour and wellbeing, including depression and anxiety. Two nurses were trained in the use and purpose of the SF-36. The SF-36 was administered by the nurses and one author.

Patient data. The demographic data, time on dialysis and underlying aetiology of ESRD were assessed via unit records. Underlying kidney disease was classified by clinical criteria and not by histopathology. Educational level was graded as: 1 - up to 4 years of schooling; 2 - more than 4 years. Every patient was assigned a low, medium or high risk index based on comorbidity, as described by Khan et $\mathrm{al}^{10}$. Khan's comorbidity index takes into consideration age in three classes and nine comorbidities: diabetes, myocardial infarction, angina pectoris, congestive heart failure, liver cirrhosis, obstructive pulmonary disease, systemic collagen disease, pulmonary fibrosis and visceral malignancies. The laboratory results are those routinely measured in haemodialysis patients and correspond to the mean of three months, including the month when SF-36 was administered and the months before and after its administration. Creatinine, haemoglobin, albumin, calcium and phosphorus were measured with standard methods by the same laboratory throughout the study. KtV (dialysis dose index) was estimated using a second-generation Daugirdas formula ${ }^{11}$, and like other laboratory results, is presented as a three-month average.

Statistical analyses. Continuous and category variables are presented as mean \pm SD and percentages, respectively. Scores related to the eight domains of HRQOL were generated by a specific SF-36 programme. For univariate analysis, we calculated the Pearson correlation coefficient of age, time on dialysis and laboratory results with scores generated by the SF-36. We used the
Spearman coefficient to estimate the correlation between comorbidity and HRQOL scores. For multivariate analysis, we employed stepwise linear regression including the following clinical and laboratory variables: sex, age, time on dialysis, comorbidity, creatinine, haemoglobin, albumin, calcium-phosphorus product and KtV. Statistical significance was considered to be a $\mathrm{P}$ value of $<0.05$. All the statistical analyses were carried out using the SPSS version 13.0 package programme.

\section{RESULTS}

The mean age of the sample was $43 \pm 15$ years (range 18-83), 64.6\% were male, and mean time on dialysis was $39 \pm 44$ months (median $=19.0$; range 3-191). The most prevalent primary kidney diseases were glomerulonephritis (49.4\%) and hypertension (26.8\%). The complete demographic and laboratory data are shown in Table 1.

Amongst the eight domains related to quality of life, role-physical presented the lowest score $(35.0 \pm 43.0)$ and social function the highest $(64.3 \pm 27.7)$, as shown in Table 2 .

In the univariate analysis, all eight variables studied were correlated with at least one HRQOL domain. However, age (except for bodily pain) and albumin (except for role-emotional) were correlated with seven of eight domains. The correlations were negative for age and positive for albuminemia. The correlation coefficients are shown in Table 3 and 4. Comorbidity was associated with physical function, role-physical and roleemotional (Table 5).

In the multivariate analysis, only age and albumin were associated with various life-quality domains. Nonetheless, time on dialysis, haemoglobin and calcium-phosphorus product were each associated with a specific domain, respectively, physical function, bodily pain and vitality, as shown in Table 6.

\section{DisCUSSION}

Our sample is very singular: there were few diabetics, so young patients with predominance of glomerulonephritis as the primary kidney disease made up the majority, with a small number of 


\section{Table 1. Patient data}

\begin{tabular}{|c|c|}
\hline \multicolumn{2}{|l|}{ Clinical and laboratory variables } \\
\hline \multicolumn{2}{|l|}{ Sex } \\
\hline Male & $106(64.6)$ \\
\hline Female & $58(35.4)$ \\
\hline Age & $43 \pm 15$ \\
\hline \multicolumn{2}{|l|}{ Race } \\
\hline White & $66(40.2)$ \\
\hline Mulatto & $82(50.0)$ \\
\hline Black & $16(9.8)$ \\
\hline \multicolumn{2}{|l|}{ Level of education } \\
\hline Grade 1 & $128(78.0)$ \\
\hline Grade 2 & $36(22.0)$ \\
\hline \multicolumn{2}{|l|}{ Job } \\
\hline No & $140(85.4)$ \\
\hline Yes & $24(14.6)$ \\
\hline \multicolumn{2}{|l|}{ Income (monthly) } \\
\hline$\leq \mathrm{US} \$ 200$ & $119(72.6)$ \\
\hline$>$ US\$ 200 & $45(27.4)$ \\
\hline Time on dialysis (months) & $\begin{array}{c}39 \pm 44 \\
\text { (median }=19.0 \text { ) }\end{array}$ \\
\hline \multicolumn{2}{|l|}{ Primary kidney disease } \\
\hline Glomerulonephritis & $81(49.4)$ \\
\hline Hypertension & $44(26.8)$ \\
\hline Diabetes & $12(7.3)$ \\
\hline Polycystic kidney disease & $8(4.9)$ \\
\hline Chronic pyelonephritis & $8(4.9)$ \\
\hline Lupus & $7(4.3)$ \\
\hline Obstructive uropathy & $4(2.4)$ \\
\hline \multicolumn{2}{|l|}{ Comorbidity* } \\
\hline Low risk & $124(75.6)$ \\
\hline Medium risk & $29(17.7)$ \\
\hline High risk & $11(6.7)$ \\
\hline Creatinine $(\mathrm{mg} / \mathrm{dl})$ & $13.0 \pm 3.3$ \\
\hline Haemoglobin $(\mathrm{g} / \mathrm{dl})$ & $10.0 \pm 1.9$ \\
\hline Albumin $(\mathrm{g} / \mathrm{dl})$ & $4.3 \pm 0.6$ \\
\hline Calcium-phosphorus product $\left(\mathrm{mg}^{2} / \mathrm{dl}^{2}\right)$ & $66.3 \pm 23.7$ \\
\hline $\mathrm{KtV}$ & $1.49 \pm 0.3$ \\
\hline
\end{tabular}

Data are means $\pm \mathrm{SD}$, or percentages (in parentheses)

*Khan index

participants with advanced comorbidity. The worldwide pattern is the reverse: diabetes is the principal primary kidney disease, with predominance of elderly and high-risk patients ${ }^{12}$.

This is a typical sample of underdeveloped areas of the globe, where infectious diseases are the main public health problem and medical assistance to patients with chronic diseases are inadequate. Indeed, diabetics in these regions die from cardiac complications before developing ESRD, which appears after many years the onset of diabetes. Brazil has socioeconomic disparities 
Table 2. M ean scores related to quality of life

\begin{tabular}{|lc|}
\hline Domains & Score \\
\hline Physical function & $59,0 \pm 27,0$ \\
Role-physical & $35,0 \pm 43,0$ \\
Bodily pain & $59,0 \pm 28,0$ \\
General health & $43,0 \pm 22,0$ \\
Vitality & $52,0 \pm 23,0$ \\
Social function & $64,3 \pm 27,7$ \\
Role-emotional & $43,0 \pm 45,0$ \\
Mental health & $64,0 \pm 23,0$ \\
\hline
\end{tabular}

and many regions due to its continental size, resulting in different profiles of haemodialysis patients. But even in larger and richer cities of southeast Brazil - and indeed in many large cities of the world - patients with the profile of ours can be found in poor and peripheral areas.

Despite the underdeveloped profile, our HD patients presented role-physical as the lowest (worst) score and social function and mental health as the highest (best) scores. Role-physical pertains to physical, and social function and mental health to the mental component of HRQOL This is in accordance to North American and European results, which show mental aspects less affected than physical ones in HD patients $3,13,14$. Considering the young age and low-grade comorbidity of our patients, it is serious to find so much impact in the role-physical category. This smaller

Table 3. Pearson correlations between laboratory variables and quality of life

\begin{tabular}{|c|c|c|c|c|c|c|c|c|c|c|}
\hline \multirow[t]{3}{*}{ Domains } & \multicolumn{10}{|c|}{ Laboratory variables } \\
\hline & \multicolumn{2}{|c|}{$\mathrm{Cr}$} & \multicolumn{2}{|c|}{$\mathrm{Hb}$} & \multicolumn{2}{|c|}{ Alb } & \multicolumn{2}{|c|}{$\mathrm{CaP}$} & \multicolumn{2}{|c|}{$\mathrm{KtV}$} \\
\hline & $\mathrm{r}$ & $P$ & $\mathrm{r}$ & $P$ & $\mathrm{r}$ & P & $\mathrm{r}$ & $\mathrm{P}$ & $\mathrm{r}$ & $\mathrm{P}$ \\
\hline $\mathrm{PF}$ & 0.140 & 0.080 & 0.047 & 0.558 & 0.301 & $<0.001$ & 0.036 & 0.648 & -0.219 & 0.005 \\
\hline $\mathrm{RP}$ & 0.118 & 0.140 & 0.123 & 0.121 & 0.176 & 0.026 & 0.146 & 0.066 & -0.015 & 0.846 \\
\hline $\mathrm{BP}$ & 0.206 & 0.009 & 0.209 & 0.007 & 0.308 & $<0.001$ & -0.004 & 0.956 & -0.076 & 0.336 \\
\hline $\mathrm{GH}$ & -0.044 & 0.578 & 0.080 & 0.313 & 0.242 & 0.002 & -0.046 & 0.562 & -0.039 & 0.622 \\
\hline VT & 0.059 & 0.457 & 0.157 & 0.047 & 0.258 & 0.001 & -0.090 & 0.257 & 0.010 & 0.893 \\
\hline $\mathrm{SF}$ & 0.098 & 0.218 & 0.107 & 0.179 & 0.276 & $<0.001$ & 0.199 & 0.011 & -0.055 & 0.483 \\
\hline $\mathrm{RE}$ & 0.058 & 0.470 & 0.078 & 0.326 & 0.129 & 0.105 & 0.076 & 0.340 & -0.119 & 0.136 \\
\hline $\mathrm{MH}$ & 0.035 & 0.656 & 0.119 & 0.132 & 0.168 & 0.034 & -0.001 & 0.987 & 0.035 & 0.656 \\
\hline
\end{tabular}

PF: physical function; RP: role-physical; BP: bodily pain; GH: general health; VT: vitality; SF: social function; RE: role-emotional; $\mathrm{MH}$ : mental health; Cr: creatinine (mg/dl); $\mathrm{Hb}$ : haemoglobin (g/dl); Alb: albumin (g/dl); CaP: calcium-phosphorus product $\left(\mathrm{mg}^{2} / \mathrm{dl}^{2}\right)$.

Table 4. Pearson correlations between age and time on dialysis and quality of life

\begin{tabular}{|lcccc|}
\hline Domains & & \multicolumn{2}{c|}{ Clinical variables } & Time on dialysis \\
& $\mathrm{r}$ & $\mathrm{P}$ & $\mathrm{r}$ & $\mathrm{P}$ \\
\hline Physical function & -0.259 & 0.001 & -0.133 & 0.104 \\
Role-physical & -0.194 & 0.017 & -0.064 & 0.432 \\
Bodily pain & -0.152 & 0.063 & -0.109 & 0.182 \\
General health & -0.200 & 0.014 & -0.155 & 0.058 \\
Vitality & -0.275 & $<0.001$ & -0.029 & 0.723 \\
Social function & -0.279 & $<0.001$ & -0.012 & 0.884 \\
Role-emotional & -0.213 & 0.008 & 0.042 & 0.609 \\
Mental health & -0.195 & 0.016 & 0.028 & 0.727 \\
\hline
\end{tabular}


Table 5. Spearman correlations between comorbidity and quality of life

\begin{tabular}{|lcc|}
\hline Domains & \multicolumn{2}{c|}{ Comorbidity* } \\
\hline Physical function & $\mathrm{r}$ & $\mathrm{P}$ \\
Role-physical & -0.183 & 0.019 \\
Bodily pain & -0.198 & 0.011 \\
General health & -0.107 & 0.171 \\
Vitality & -0.130 & 0.096 \\
Social function & -0.093 & 0.232 \\
Role-emotional & -0.109 & 0.161 \\
Mental health & -0.188 & 0.015 \\
& -0.041 & 0.597 \\
\hline
\end{tabular}

*Khan index

Table 6. Stepwise linear regression of clinical and laboratory variables with quality of life

\begin{tabular}{|lcccccccc|}
\hline Variables & & & \multicolumn{7}{c}{ Domains } & & & \\
& PF & RP & BP & GH & VT & SF & RE & MH \\
\hline Age & - & - & - & - & - & - & - & - \\
Time on dialysis & $-0.312^{\dagger}$ & $-0.262^{\dagger}$ & & $-0.232^{\dagger}$ & $-0.298^{\dagger}$ & $-0.293^{\dagger}$ & $-0.260^{\dagger}$ & $-0.217^{\dagger}$ \\
Hb & & & & & & & & \\
Alb & $0.218^{\dagger}$ & & $0.175^{*}$ & & & & & \\
CaP & & & $0.276^{\dagger}$ & $0.268^{\dagger}$ & $0.270^{\dagger}$ & $0.250^{\dagger}$ & & \\
\hline
\end{tabular}

PF: physical function; RP: role-physical; BP: bodily pain; GH: general health; VT: vitality; SF: social function; RE: role-emotional; $\mathrm{MH}$ : mental health; $\mathrm{Hb}$ : haemoglobin $(\mathrm{g} / \mathrm{dl})$; Alb: albumin $(\mathrm{g} / \mathrm{dl}) ; \mathrm{CaP}$ : calcium-phosphorus product $\left(\mathrm{mg}^{2} / \mathrm{dl}^{2}\right)$

${ }^{*} \mathrm{p}<0.05 .{ }^{\dagger} \mathrm{p}<0.01$

role-physical, together with poor social status and treatment restrictions, can be one determinant of the low percentage of patients with a job. Efficient interventions with physical conditioning programmes are reported in the literature ${ }^{15,16}$. We think that better physical status will lead to more job opportunities amongst patients in such a productive age range.

The quality of treatment evaluated by the laboratory variables can be considered good. The mean laboratory results are adequate to recommended targets for abuminemia and dose of dialysis ${ }^{17}$. The mean haemoglobin is $1 \mathrm{~g} /$ dl below the target. The calcium-phosphorus product is over recommended level, reflecting the difficulty in practice to control it adequately.

Age and albumin were the most important correlators with HRQOL. Their correlation was maintained in the multivariate model. Most information about the age effect on HRQOL comes from research on patients older than 65 . In these, quality of life is lower than in the general agematched population ${ }^{18,19}$. The average age of our sample is far below 65 and we found age negatively associated with both physical and mental aspects, in contrast to various studies where ageing affects more physical than mental components of quality of life 20,21 . 
Albumin is a traditional marker of morbidity and mortality ${ }^{22}$, and in our study it was positively associated with five of eight HRQOL domains. Its level decreases because of malnutrition or inflammatory activity. Unfortunately, a cross-sectional study design cannot clarify this association: Does low albumin affect HRQOL or low HRQOL interfere with diet, causing low albumin?

Comorbidity was correlated with three domains in the univariate analysis, but contrary to our expectations, not in the multivariate model. Probably this occurred because despite the grade of comorbidity, the consequences expressed by laboratory markers, such albumin, are the most important association. We can establish that HRQOL in our sample can be more affected in patients with low albumin than those patients with comorbidities but without such alteration.

Calcium-phosphorus product, like albumin, is also a strong predictor of morbidity and mortality in HD patients ${ }^{23}$. This is derived from the deposition of calcium-phosphorus in soft tissues and also in arteries, affecting coronary and myocardial function, as well as causing ischemia of body segments ${ }^{24}$. Even though calcium-phosphorus product was associated with only one domain, we considered vitality a strategic domain, and believe this association has to be borne in mind by health providers treating patients with high calciumphosphorus product. We did not find this association in literature. Recent study reveals hypercalcaemia, but not calcium-phosphorus product, associated with poor mental health ${ }^{25}$.

It was surprising to us that time on dialysis was only associated with physical function, since time on dialysis is associated with so many medical complications. The median time on dialysis of only 19 months in our sample can be an explanation for the lack of this association.

We intentionally chose medical instead of socioeconomic factors to analyze due to the

\section{REFERENCES}

1. Cleary PD, Wilson PD, Fowler FJ. Health-related quality of life in HIV-infected persons: a conceptual model. In: Dimsdale JE, Baum A. Quality of life in behavioural medicine research. New Jersey: Lawrence Erlbaum Associates, 1995; 191-204. homogeneity of poor socioeconomic profile. It seems to us that some clinical variables studied can be modified, unlike the socioeconomic situation of our patients. The results reported here can improve the quality of care by achieving interventions concerning sub-groups at risk of poor outcomes. Control of diet and inflammation by checking albumin was always our concern and needs more attention regarding HRQOL. In the same way, control of calcium-phosphorus product gains importance in the perspective of life quality. Finally, the poor level related to rolephysical indicates the need for exercise programmmes, which have been shown to be efficient in literature.

There are several limitations to this study. Firstly, the sample size is modest. Secondly, our results may not hold for patients without the singular characteristics as ours. Thirdly, crosssectional evaluation makes it difficult to draw conclusions regarding causality by correlations and regression analysis. However, despite these limitations, the strength of our research regards its objective, in other words, the fact our analysis involves individual life quality domains helps to determine individual aspects of HRQOL which require priority attention by health care providers of similar patients.

In conclusion, clinical and laboratory variables such as age and albumin were significant and independently correlated with quality of life concerning almost all HRQOL domains assessed by SF-36. Vitality, a very strategic life-quality domain, was also associated with a third variable: the calcium-phosphorus product. Interventions must be planned to control albumin and calciumphosphorus product, as well as close follow-up of ageing in patients who remain on dialysis without transplantation. Finally, the very low score in rolephysical domain in such a youthful sample calls for particularly efficient interventions.

2. Garratt A, Schmidt L, MacKintosh A, Fitzpatrick R. Quality of life measurement: bibliography study of patient assessed health outcome measures. BMJ 2002; 324: 1417-9.

3. Mittal SK, Ahern L, Fiaster E, MaesaKa JK. Self-assessed physical and mental function of haemodialysis patients. Nephrol Dial Transplant 2001; 16: 1387-94. 
4. Leggat JE, Swartz, RD, Port FK. Withdrawal from dialysis: a review with emphasis on the black experience. Adv Renal Replace Ther 1997; 4: 22-9.

5. Cohen LM, Germain MJ, Poppel DM. Practical considerations in dialysis withdrawal. JAMA 2003; 289: 2113-9.

6. Pereira LC, Chang J, Fadil-Romão MA, Abensur $\mathrm{H}$, ARaÚjo MRT, Noronha IL ET AL. [Health-related quality of life in renal transplant patients]. J Bras Nefrol 2003; 25: 10-6.

7. Ogutmen B, Yildrim A, Sever MS, Bozfakioglus S, AtAMAN R, EREK E ET AL. Health-related quality of life after kidney transplantation in comparison intermittent hemodialysis, peritoneal dialysis, and normal controls. Transplant Proc 2006; 38: 419-21.

8. LOPEs AA, Bragg-Gresham JL, Goodkin DA, Fukuhara S, MAPES DL, Young EW ET AL Factors associated with health-related quality of life among hemodialysis patients in the DOPPS. Qual Life Res 2007; 16: 545-57.

9. Cicconelu RM, FerRaz MB, Santos W, Meinão I, QuARESMA MR. [Translation to portuguese and validation of the generic questionnaire of quality of life SF-36 (Brazil SF-36)]. Rev Bras Reumatol 1999; 39: 143-50.

10. Khan IH, Campbell MK, Cantarovich D, Catto GRD, DelCRoIX C, EDWARD N ET AL. Survival on renal replacement therapy in Europe: is there a centre effects? Nephrol Dial Tranplant 1996; 11: 300-7.

11. Daugirdas JT. Second generation logarithymic estimates of single-pool variable volume Kt-V: an analysis of error. J Am Soc Nephrol 1993; 4: 205-13.

12. Hamer RA, El NAHAS AM. The burden of chronic kidney disease. BMJ 2006; 332: 563-4.

13. Perneger TV, Leski M, Chopard-Stoermann C, Martin P. Assessment of health status in chronic hemodialysis patients. J Nephrol 1995; 5: 1826-34.

14. Kusek JW, Greene P, Wang S, Beck G, West D, JAMERSON K ET AL. Cross-sectional study health-related quality of life in African American with chronic renal insufficiency. Am J Kidney Dis 2002; 39: 513-24.

15. Tawney KW, Tawney PJW, Hiadick GH, Hogan SL, Falk RJ, WeAVER C ET AL. The life readiness program: a physical rehabilitation program for patients on hemodialysis. Am J Kidney Dis 2000; 36: 581-91.
16. Vilsteren MCB, Greef MH, Huisman RM. The effects of a low-to-moderate intensity pre-conditioning exercise programme linked with exercise counselling for sedentary haemodialysis patients in The Netherlands: results of a randomized clinical trial. Nephrol Dial Transplant 2005; 20: 141-6.

17. National Kidney Foundation: NKF-DOQI. Clinical guidelines for hemodialysis adequacy. Am J Kidney Dis 2001; 37 (Suppl 1): 7-64.

18. Altintepe L, Levendoglu F, Okudan N, Guney I, Ciшi S, Ugurlu H ET al. Physical disability, psychological status and health-related quality of life in older hemodialysis patients and age-matched controls. Hemodial Int 2006; 10: 260-6.

19. Merkus MP, Jager KJ, Dekker FW, Boeschoten EW, SteVENS P, KREDIET RT. Quality of life in patients on chronic dialysis: self-assessment 3 months after the start of treatment. Am J Kidney Dis 1997; 29: 584-92.

20. Singer MA, Hopman WM, MacKenzie TA. Physical functioning and mental health in patients with chronic medical conditions. Qual Life Res 1999; 8: 687-91.

21. Lamping DL, Constantinovici N, Roderick P, Normand C, Henderson L, HaRris S et aL. Clinical outcomes, quality of life, and costs in the North Thames dialysis Study of elderly people on dialysis: a prospective cohort study. Lancet 2000; 356: 1543-50.

22. BRISTIAN BR. Role of the systemic inflammatory response syndrome in the development of proteincalorie malnutrition in end-stage renal disease. Am J Kidney Dis 1998; 32 (Suppl. 4): 113-7.

23. Bцоск GA, Port FK. Re-evaluation of risks associated with hyperphosphatemia and hyperparathyroidism in dialysis patients: recommendations for a change in management. Am J Kidney Dis 2000; 35: 1226-37.

24. Goodman WG, Goldin J, KuIzon BD. Coronary-artery calcification in young adults with end-stage renal disease who are undergoing dialysis. N Engl J Med 2000, 342: 1478-83.

25. TANaKa M, Yamazaki S, Hayashino Y, Fukuhara S, AKiba T, SaIto A ET al. Hypercalcaemia is associated with poor mental health in haemodialysis patients: results from Japan DOPPS. Nephrol Dial Tranplant 2007; 22: 1658-64. 